\title{
Mindfulness and Leadership: A Critical Reflection
}

\author{
Servaas van Beekum, drs \\ Correspondence: Servaas van Beekum, 158 Wellington Street, Bondi Beach 2026, NSW, Australia. Tel: +61400460429
}

\author{
Received: October 29, 2015 Accepted: November 2, 2015 Online Published: November 5, 2015 \\ doi:10.11114/bms.v2i1.1190 URL: http://dx.doi.org/10.11114/bms.v2i1.1190
}

\begin{abstract}
This paper critically highlights the history and the current use of the concept of mindfulness, from its Buddhist roots via medical application and organizational consulting into its application as a management tool. The paper puts the concept of mindfulness in its historical context, mentions some of the controversies the 'brand of mindfulness' has stirred and prefers the term 'being mindful' over 'mindfulness'. However, as Stolarov (1992) argued: the mind in isolation is a myth. The mind itself is social and relational in such a way that the intrapsychic inner world is directly related to the relational context in which it is embedded. In consulting and management, being mindful is, beyond an individual process of growth and development, also relational, recognizing that there are two or more entities working in a mutual and reciprocal process.

Once we apply 'being mindful' on professionals in organizations it is clear that this can improve the wellbeing of leaders, managers and staff and the overall effectiveness of an organization. In the organizational literature the concept of 'deep thinking' is explored in marketing and sales. The paper promotes, explores and elaborates the concept of being mindful, including deep thinking, as essential for practical and spiritual aspects of organizational and corporate life, in particular for the transformational tasks of leaders and managers. Eight characteristics of mindful leadership are elaborated.
\end{abstract}

Finally the potential parallel process of the rise of mindfulness and transactional analysis, stands out as a warning.

Keywords: mindfulness, mindful consulting, relational, deep thinking, transformation, leadership

\section{Mindfulness}

Mindfulness, as meant in the original Sanskrit word 'sati', is an essential part of Buddhist practice and promotes an attentive awareness of the reality of things in the here and now. Mindfulness is one of many translations of the word sati. Others include: awareness, inspection, recollection or retention. Mindfulness is pre-symbolic as Gunaratana explains in his famous 'Mindfulness in plain English': "Mindfulness can be experienced and it can be described, but keep in mind that the words are only fingers pointing at the moon. They are not the thing itself" (Gunaratana, 2011, p.131). Mindfulness is the center of and key to the process of Vipassana meditation. It is both the goal of this meditation and the means to that end. One can reach mindfulness by being ever more mindful.

In every day life, mindfulness stands for "the active, watchful mind" (Rhys Davids, 1881, p.107), which means not only, "moment to moment awareness of present events," but also, "remembering to be aware of something or to do something at a designated time in the future" (Mind \& Life Institute, 2014).

In medicine, in particular in psychiatry, mindfulness practice is used as an antidote to delusion, supposedly alleviating a variety of mental and physical conditions, such as obsessive-compulsive disorder, anxiety, depression and drug addiction. Stress reduction programs have sparked the application of mindfulness ideas and practices (Brown, Ryan \& Creswell 2007). Neuroscience claims that mindfulness practice rewires the brain (Siegel, 2007). Mindfulness training increases activity in the left prefrontal cortex - a predictor of happiness and well-being. And it boosts the immune response, helping to defend against illness (Davison \& Kabat-Zinn, 2003).

Here and now mindfulness and awareness is not a prerogative of Buddhism or medicine. Gestalt psychology is based on the concept of here and now contact rooted in here and now awareness. This includes body sensations, awareness of self and others, of figure and ground and of the active dynamic between these dichotomies. Awareness is a short lived split second flowing phase just as one focuses one's eyes and mind on an object. It takes place before one starts thinking about it, before one's mind says: "Oh, it is." In terms of practice, Gestalt psychology promotes that being in contact with self and other creates change. Simply being open to self and other, changes us (Polster \& Polster, 1974; Orange, 2012). 
Transactional analysis connects its concept of autonomy with relational script-free awareness of the way of making contact with self and other (Berne, 1967; van Beekum \& Krijgsman, 2000). Berne (1972) uses the image of the Martian who comes down to earth, observing without any preconceived notions, only to see and experience the world exactly as it is. Personal construct psychology, a cognitive approach, discriminates between levels of awareness. A high level of awareness shows itself in being aware of what is going on, as and when it is happening. A lower level of awareness shows up when for example one reads something disturbing which makes one feel angry but in the moment one is not sure why (Kelly, 1955/1991).

Psychoanalysis has taught that while we can be fully aware of what is going on in our conscious minds, we have no idea of what information and processes are stored in the pre-conscious and unconscious mind. The pre-conscious contains thoughts and feelings that we are not currently aware of, but which can be brought to consciousness through reflection, therapy and analysis. It exists just below the level of consciousness. The unconscious contains all sorts of disturbing, though significant material, which we often want to keep out of awareness because it is too threatening to acknowledge in full (Freud, 1915).

Based on Buddhist meditation and its application in medicine and clinical psychology, mindfulness is obviously enjoying a growing popularity as a practice for daily life. Over time, the meaning of mindfulness has become more pragmatic than philosophical, varying from mindfulness as a mental state, to mindfulness as a set of skills and techniques. Mindfulness is increasingly seen as a mode of being which can be practiced anywhere, including the workplace. Mindfulness meditation involves using one's senses to help focus one's attention on the present. It focuses on the intentional, accepting and non-judgmental attention to one's emotions, thoughts and sensations occurring in the here and now. Skilful psychotherapy helps to explore the thinking patterns and emotions that emerge during mindfulness exercises so that the source of one's problems can be exposed and new insights can be created.

The Mindfulness Journal, a quarterly academic journal since 2010, publishes peer-reviewed papers that examine the latest research findings and best practices in mindfulness. Its viewpoints include "psychology, psychiatry, medicine, neurobiology, psychoneuroendocrinology, cognitive, behavioural, cultural, philosophy, spirituality, and wisdom traditions" (Mindfulness, 2014). This seems to be a far cry from its original Buddhist's roots but it shows clearly what contemporary mindfulness stands for. And as a result, the business of mindfulness attracts criticism: "The modern description and practice of mindfulness are certainly valuable, as thousands of people have discovered for themselves through their own practice. But this doesn't take away from the fact that the modern understanding of mindfulness departs significantly from the Buddha's own account of sati" (Wallace, 2006). Karnaze writes about the 'mindfulness construct' as a-political, escapist and illusory meditation, used by Westerners to tinker with the next Eastern 'toy', be it yoga or mindfulness. Yet she defends that "mindfulness paves the way for our future. And meditation is a powerful tool that I wouldn't try to replace" (Karnaze, 2014).

Mindfulness has become a trendy movement, a brand, some would argue "an industry, mocked McMindfulness" (Whitaker, 2013), by creating a modern looking, sellable product, modifying old wine in a new bag, integrating philosophical, religious, medical and psychological elements and using Buddha for the goodwill factor.

When 'mindfulness' in its current popularity becomes a movement, we may enter into the dangers of what Jung called mass-mindedness (Jung, 1970). When classical containers of society, like church, family or community loose their influence, people are loosing their roots, become increasingly instable, suggestible and insecure and look for the containment of larger movements for making meaning of their lives. Jung felt that the larger the size of the movement, the greater are the dangers of people being moved by impersonal and overwhelming forces and by herd psychology, because the overall level of consciousness in mass movements is lower. To protect from these external forces, Jung promoted a fundamental inner mind change, which he called metanoia, to be reached by dreamwork.

Regular practice of working with their dreams allows people to discover their inner world. Watching the psyche's creativity and unfolding insights every night in our dreams, helps to lead the "responsible life" that Jung saw as a consequence of individuation, in cohesion with becoming increasingly conscious of our duties to our communities. This metanoia, the fundamental inner mind change, does not take us into isolation or cut off from society, but rather makes us aware of how we all are one in a complexity of interdependence.

\section{Mindful Consulting}

Jung would be the first to focus on a missing aspect in mindfulness, the presence of 'other'. In all of the above mentioned applications, mindfulness is mainly used as a tool for individual health, personal development and spiritual healing, applicable in almost every context but in social isolation as if there is no other. Mindfulness is not seen as a relational quality, nor seen as rooted in early relational patterns. When there is some other it is someone who will benefit later from the cleansing done by the mindful one. Although mindfulness courses include a trainer or a guru, mindfulness operates often as an individual quality, out of context with others, as a baby without a mother. The relational aspect is 
not focused on and hardly mentioned.

Intrapsychic life is driven by thoughts, feelings and all what regulates inner life, on conscious and unconscious levels. Heller (2010) argues that the intrapsychic is embedded in a dynamic intersubjective field. Embedded relational mindful therapy focuses on the therapeutic dyad which is used to understand one's present moment experience of connectedness with the therapist, in the history of one's of early attachment issues. Stolorow adds that the isolated mind is a myth. Intrapsychic material is derived from interpersonal, environmental, linguistic and cultural experiences (Stolorow, 1992). Sullivan adds that "a personality can never be isolated from the complex of interpersonal relationship in which the person lives" (Sullivan, 1940, p.90). The mind is social, the intrapsychic inner world is directly related to its relational context. In a reciprocal evolving process, culture and mind are also emergent from each other. Laing argues that isolated selves are at the core of psychotic and schizoid individuals. In his description of ontological insecurity he describes how isolated individuals do not experience themselves as real or alive, because of lack of relational cohesiveness and consistency, which makes them preoccupied with preserving their own existence (Laing, 1959).

A more relational approach of mindfulness can be found in the literature and practice of consultancy. The client consultant dyad frames mindfulness from the start as a mutual, relational and reciprocal process, in which consultants and clients engage in an ongoing learning process. In other words: the baby hás a mother and both learn in the process. The consultant does not apply a specific mindset to an organisational issue, but enters with the client into the void of an unknown outcome, where unformulated client experience (Stern, 2003) emerges, through a relational experience of curiosity and acceptance or disgust and rejection.

In her introduction of "Mindful Consulting" (White \& Izod, 2009), White uses the wardrobe metaphor to differentiate mindfulness from using different prefabricated mindsets. White equates the consultant using different mindsets for different tasks (e.g. Mintzberg, 2004), with pulling the right costume out of the wardrobe when supposed to be necessary, mostly recreating the same categories for which the wardrobe has supply. In contrast, "mindfulness is about putting together a wardrobe that has the requisite variety for the roles required of a consultant and then making sure that you do not just wear the items that are comfortable" (White \& Izod, 2009, p. XXIX).

In mindful consulting, the consultant and client give up what is familiar and break with known routine, which is exciting, challenging and threatening for both. As such, mindful consulting leans closely to psychoanalytically informed approaches, which extends the work into uncontrollable areas.

Based on the myth of controllability, however, organizations often demand to get quick answers on how-to-manage-things-better-tomorrow questions. They want a well-structured plan, predictable outcomes, and measurable performance indicators. Mindful consultants, especially the more analytically minded, take on the challenge of relating with the deeper complexity and don't succumb to their own and their client's anxieties. On the contrary, they consider it part of their professional ethos to provide the containment for organizations to deal mindfully with complexity and anxiety.

\section{Deep Thinking}

The concept of mindfulness covers a spectrum from an ancient Buddhist meditational attitude via intrapsychic life and relational consulting to a commercial product. To avoid being caught in a fight for the right understanding of mindfulness or for politically correct conceptualization, this paper uses the concept 'mindful' in a generic way, not particularly bound to a school, an approach, a brand or a movement.

Being mindful in essence comes down to allow the experience of deeper thinking, promoted by philosophers, poets and psychologists, even long before Freud. By deeper thinking in the here and now, one is in contact with oneself and other, with one's own and other' deeper sensations, emotions, drives, thoughts, motivations and shadows, including the context in which all this takes place. Deeper thinking as an expression of being mindful is a state of awareness "that enables us to be flexible and receptive and to have presence" (Siegel, 2010).

As a broad generalisation, corporates, executives and senior managers are not easily associated with in depth learning or reflection. This is not a comment by an observant social scientist but is acknowledged in the corporate sector itself. In their book Marketing Metaphoria, Harvard lecturers Gerald and Lindsay Zaltman (2008) discuss the lack of what they call deeper thinking among leaders and managers.

Most contemporary research about organizational behaviour, addresses the conscious level, they write, the visible $10 \%$ of the iceberg. And they argue that deeper insight can only come from making a mindful connection with the more hidden layers of our existence. That more unconscious layer eventually determines our behaviour, it explains why people don't do what they promised to do, why teams sabotage their own jointly taken decisions and why organizations perform under par, despite all good intentions.

There is an anecdote about the late Harvard professor Anthony Athos. When the weather was good, he was often spotted 
sitting under a tree on the campus at the Harvard Business School, with a vague expression on his face. Asked what he did there, his answer was: "Nothing". His Harvard colleagues rolled their eyes and walked away from him, wondering if he was still compos mentis. However, this man was known for his deep insights, thoughts and questions during staff and management meetings. He just took time to think deeper and to be more mindful.

Executive coaches are used to see highflying leaders, managers and ceo's from a variety of industries, who are under daily pressure to make clear, simple, unilateral and fast decisions. In the process of mindful coaching, a meta-level of thinking is introduced as a first step to being more mindful. A second step is allowing more complexity, a third step more time, a fourth step more intrapersonal reflection. In this process the leaders buy time to think, they buy time to be more mindful, in a way that they can interconnect all the four quadrants described by Wilber (1996), the self, the self in relationship, the culture and the collective outcomes. The higher up in the organization this is practiced, the more the whole organization benefits.

The Zaltmans, who are marketing experts, expand this by calling on managers to learn to listen to internal sources of information as 'deep metaphors'. They claim that seven metaphors such as balance (as in work-life balance), transformation (as in sustainable change), travel (as in the travel of life), containment (as in what belongs and what doesn't), connectivity (as in feeling of belonging or being excluded), resources (for survival) and control (have control or let go of control) describe $70 \%$ of our internal emotions and that these are relevant for working in a corporation. Being mindful of them adds value to the work. Other related reading from within the business world can be found in Zaltman (2003) and Sawyer (2006).

\section{Transformation and Leadership}

Wilfried Bion (1961), known for promoting to study unconscious process in social systems, stressed the importance of taking time for reflection. He advised leaders and managers to create emotional space by taking time outs, by making space for relaxation or daydreaming and to eschew memory. He would encourage that professionals engage in activities such as yoga, meditation or tai chi. One could think that a mindfulness training fits in there very well. It is Bion's thinking that leaders and managers need to develop a capacity to contain the anxieties connected to their roles and that they can only do so from a mindful place.

Leaders and managers are in in charge of processes of change and transformation. They often are familiar with the following scenario: the organization has gone through a 'change management process'. This included the definition of goals, extended training days for staff and coaching of management. But, many days and dollars later, everything is still the same. Or they have sent some staff members to a training course from which they returned with new enthusiasm, one could even say that they were 'changed', but in the shortest of times these staff members were back to their previous selves from before the training. Obviously there was some change but then it reverted back to what was before, which in effect meant that nothing had changed.

This is not remarkable because this sort of process is inherent in change: change can be made unchanged and it will happen when the stimulusof the change, like the trainer, the powerpoint presentation or the article, disappears. The used metaphor is the water kettle in the kitchen, heated up to 100 degrees, the water has changed, then turn off the heater and the water will cool down till what is was at the start. Change is temporarily and depending on an outside resource.

In contrast, a consulting process, which focuses on permanent and sustainable change, needs to mobilize internal resources of the organization. This type of change is transformational and essential for every organization that wants to be in the business of continuing innovation. When change can be compared with boiling water, the metaphor for transformation is making an omelette. One mixes eggs and veggies with herbs, adds oil and heat. When the omelette is there, one will never be able to revert the parts back to where it all came from. New connections are made, a new construction, even a new taste. The ingredients have transformed into something new: the omelette. And there is more: to make this new outcome one had to break the eggs, cut the vegies and grind the herbs, and add elements as oil and heat.

When leaders are in charge of a process of transformation, being mindful is the conditio sine qua non. Gutman and Pierre (2000) suggest that in a process of transformation not only conscious but also preconscious and unconscious elements need to be taken into account. Being mindful opens the door for them, it adds practical, mental, emotional and spiritual awareness. This creates a challenge in itself: these unknown elements, which leaders need to be mindful of are always floating, never crystal clear and never finished. Being mindful starts a process which is per definition non-linear, but models a zig-zag path, often uphill.

\section{Characteristics of Mindful Leadership}

A process of transformation needs a high level of awareness and an active mind and once started, it triggers the anxieties that belong to it. When leaders are the executives who carry this process, what makes them successful? Gutman and 
Pierre (2000) have listed characteristics of leadership which are needed to make emerging awareness and anxieties part of their process of reflection and not split them off and project them onto others like the staff, the government or the competitors.

- Good leadership is visionary and shows a desired direction. By having a vision a leader can create an organization that is willing to go an unknown road. Though the vision may be clear, the exact outcome may not be known and that is exactly the reason to follow the path towards that vision. Picasso is supposed to have said: "When you know exactly what the outcome will be, why would you go there it in the first place". The unknown is of interest and creates anxieties, of which leadership has to be mindful.

- Good leadership combines vision with discernment of staying with one's desire with a sharp view. A leader must be able to explain the vision again and again, while taking social, political, economic and spiritual resistance from inside and outside the organization into account. The central question for every leader is: how do I deal with resistance that is created by the fact of me having a vision in the first place. Staying the course demands high relational mindfulness and reflection..

- Good leadership creates good followership. Followers play an active role in the vision of the leader. This sort of following does not come through dictatorial or totalitarian demands but allows the followers to become co-authors of the vision by free will, valued by the main author, the leader. To have and create a followership demands from leaders compassion and love: the leader must be able and mindful to love people, a process that often becomes reciprocal.

- Good leadership is generative and generous. By actively stimulating the own responsibilities of those who follow, leaders give the implicit message that succession is possible and valued. The leader who is conscious about his/her own succession, cares for the staff and shows generosity in thinking of the next generation. Too often we see leaders with highly inflated egos, maintaining the myth that it is all about them and that they are all mighty and in fact immortal. Generosity is an attitude, which demands being mindful.

- Good leadership creates good management and results in a healthy pairing of leader and manager as a working couple. It is the manager's task to organize the means and resources in the organization in such a way that they implement the vision of the leader. It is a shared relationship that can be very powerful en mutually enforcing. To create and sustain such a relationship needs a high level of relational mindfulness.

- Good leadership is the quality to deal with the destructive aspect of anxieties in the organization, expressed by members not being happy. That process needs psychological containment from the leader. It implies that the leader is capable to carry destruction, fear, frustrations and aggressive impulses in the organization, sometime also his own. It needs a high level of being mindful to hold others and oneself in this process while accepting that there will unavoidably be an element of destruction.

- Good leadership, finally, is to be mindful to accept that for the process of transformation, next to the working couple a third is often necessary: the consultant.

The three of them together: leader, manager and consultant, form a sustainable triangle in a transformation process. The consultant is necessary as a bridge between the external world and the internal world, because the consultant represents 'the other', the third eye, the one who brings diversity, newness and difference.

As such the consultant complements and enriches the one-on-one relationship between leader and manager. The consultant can give voice to what cannot be spoken about within the organization. The consultant also brings context, the external, to help shape the understanding within the organization. Therefor the consultant's role is conflictuous by nature and offers a healthy challenge for the tendencies of leaders to see themselves as omnipotent and all knowing. The consultant supports the working couple, to take time and think and...to be mindful.

\section{Implementation}

There seems to be enough reasons for executives to promote and develop the mental state of being mindful with themselves and in relationship with their managers and staff. Following the Zaltman's recommendations (Zaltman, 2008), learning to think deeper and learning mindful techniques is initially easier than what people often think. With focused attention and time one can make a good start. Coyle uses the term "Deep practice [which] feels a bit like exploring a dark and unfamiliar room. You start slowly; you bump into furniture, stop, think and start again. Slowly and a little painfully, you explore the space over and over, attending to errors, extending your reach into the room a bit farther each time, building a mental map until you can move through it quickly and intuitively" (Coyle, 2009 p.78). The difficulty and the challenge is to stay the course, when the process becomes harder, creates frustrations, confronts one with their own shadows or asks for more time. 
When an organization as a whole wants to introduce more time to think deeper and be mindful, an invitation to a mindful consultant to help start the process, is a first step. The consultant's role is indispensable to support and contain the emotional process of deeper thinking and deep practice. The consultant is always under pressure to make fast conclusions or interventions that are designed to make everybody feel better but s/he will not enact on that seduction. A challenge for the consultant is also to be mindful when the company uses mindfulness by stripping it from its (Buddhist) ethical foundations and simply uses it to reinforce corporate greed, aversion, and delusion, which are exactly the three roots of suffering that Buddhists seek to eliminate (Titmus, 2013).

Mindfulness is so popular, that mindfulness trainers (note that a trainer is often not a consultant) are currently asked to hold 45 minutes lunch talks for a groups of corporates to explain what mindfulness is. The invitation manifests the growing interest in mindfulness as a state of mind and its popularity, which can be considered a positive. The risk here is the expectation in the audience of being entertained for 45 minutes and that after 45 minutes everybody 'knows' what mindfulness is. The complementary risk is that the trainer colludes with those expectations. Learning to be mindful is not about slick entertainment, sexy one-liners or so called elevator statements. After all, the value of a process of learning about oneself and oneself in relation to other can only be experienced and not taught, let alone in 45 minutes. It reminds of transactional analysis in its heydays in the 1960s, when founder and top selling author Eric Berne (Games People Play, 1964/1967) was asked to do exactly that: explain in 45 minutes what transactional analysis is. It became the start of a temporary downturn for transactional analysis, because Berne had to make it simple and quickly digestible. It took away the depth and the profoundness of its theory and methodology. What else could Berne present in 45 minutes, other than a watered down version of the theory, philosophy and methodology! It took transactional analysis 20 years to grow out of the then created image of a pop- psychology and reclaim acknowledgement as the respected psychological modality it is.

Purser and Loy likened the current popular implementation of mindfulness techniques in the corporate setting to 'cow psychology,' because contented and docile cows give more milk. "One hopes that the mindfulness movement will not follow the usual trajectory of most corporate fads-unbridled enthusiasm, uncritical acceptance of the status quo, and eventual disillusionment" (Purser \& Loy, 2013).

\section{References}

Berne, E. (1964/1967). Games people play: The psychology of human relationships. London: Penguin Books.

Berne, E. (1972). What do you say after you say Hello? London: Corgi Books

Bion, W. (1961). Experiences in Groups. New York: Basic Books. http://dx.doi.org/10.4324/9780203359075

Brown, K., Ryan, R., \& Creswell, J. (2007). Mindfulness: Theoretical Foundations and Evidence for its Salutary Effects. Psychological Inquiry, 18, 211-237. http://dx.doi.org/10.1080/10478400701598298

Coyle, D. (2009). The Talent Code: Greatness isn't born. It's Grown. Here's how. New York Bantam Books

Davison, R., \& Kabat-Zinn, J. (2003). Alterations in brain and immune function produced by mindfulness meditation. Psychosomatic Medicine, 65, 564-570. http://dx.doi.org/10.1097/01.PSY.0000077505.67574.E3

Freud, S. (1915). The unconscious. Collective works. 14, 159-204.

Gunaratana, B. (2011). Mindfulness in plain English. Boston: Wisdom Publications

Gutman, D., \& Pierre, R. (2000). Consultation and Transformation: Between Shared Management and Generative Leadership. Klein, E., Gabelnick, F. \& Herr, P. (Eds) Dynamic Consultation in a Changing Workplace. Madison: Psychosocial Press p. 3-32.

Heller, M. (2010). Working in Psychological space, using the intersubjective field to access, decode and understand what lies beneath. Inside Out. http://www.insideoutjournal.com

Jung, C. (1970). Civilization in Transition. Bollingen Foundation, Collective works, 10.

Karnaze, M. (2014). The dark side of mindfulness meditation. Mindful Construct. http://mindfulconstruct.com

Kelly, G. (1955/1991). The Psychology of Personal Constructs, 1\&2. London: Routledge. First published by New York: Norton

Laing, R. D. (1959). The Divided Self, and existential Study in Sanity and Madness. London: Tavistock

Mind and Life Institute (2014). http://www.mindandlife.org/dialogues/past-conferences/ml18/

Mindfulness (2014). http://www.springer.com/psychology/cognitive+psychology/journal/12671?detailsPage=aboutThis

Mintzberg, H. (2004). Third generation management development. Training and Development, 158, 28-37. 
Orange, D. (2012). Clinical hospitality: Welcoming the face of the devastated Other. Keynote speech to the New Zealand Association of Psychotherapists' Annual Conference 2012, Wellington, Aotearoa New Zealand

Polster, E., \& Polster, M. (1974). Gestalt therapy integrated. New York, NY: Vintage Books.

Purser, R., \& Loy, D. (2013). Beyond McMindfulness. The Huffington Post. http://www.huffingtonpost.com

Rhys, D. T. (1881). Buddhist Suttas, Clarendon Press.

Sawyer, K. (Ed) (2006). The Cambridge handbook of the learning sciences. New York: Cambridge University Press

Siegel, D. (2007). The Mindful Brain. New York: Norton

Siegel, D. (2010). The Mindful Therapist. New York: Norton

Stern, D. (2003). Unformulated Experience: From Dissociation to Imagination in Psychoanalysis. Hillsdale: The Analytic Press.

Stolorow, R. (1992). The Myth of the Isolate Mind. Contexts of Being, The Intersubjective Foundations of Psychological Life. Hillsdale: The Analytic Press.

Sullivan, H. S. (1940). Conceptions of Modern Psychiatry. New York: Norton

Titus, C. (2013). The Buddha of Mindfulness. A Stress Destruction Program. http://christophertitmuss.org/blog

Van Beekum. S., \& Krijgsman, B. (2000). From Autonomy to Contact. Transactional Analysis Journal, $30,52-57$. http://dx.doi.org/10.1177/036215370003000106

Wallace, B. (2006). The attention revolution: Unlocking the power of the focused mind. Boston: Wisdom Publications

Whitaker, J. (2013). 2013 as the Year of Mindfulness: Critics and Defenders. American Buddhist Perspective. http://www.patheos.com/blogs/americanbuddhist/2013/12

White, S., \& Izod, K. (2009). Mindful Consulting. London: Karnac

Wilber, K. (1996). A Brief History of Everything. Melbourne: Hill of Content Publishing

Zaltman, G. (2003). How Customers Think: Essential Insights into the Mind of the Market. Boston: Harvard Business School Press

Zaltman, G., \& Zaltman, L. (2008). Marketing Metaphoria: What Deep Metaphors Reveal about the Minds of Consumers. Boston: Harvard Business School Press

\section{(cc) $\mathrm{EY}$}

This work is licensed under a Creative Commons Attribution 3.0 License. 